\title{
ENTRE METADES E INTEIROS: A DOCÊNCIA E A AVALIAÇÃO
}

\author{
Lúcia Schneider Hardt \\ Universidade Federal de Santa \\ Catarina \\ Marlene de Souza Dozol \\ Universidade Federal de Santa \\ Catarina
}

\begin{abstract}
Resumo
$\mathrm{O}$ artigo discute o conceito de avaliação considerandoas perspectivas da aprendizagem que por vezes são intensas, parecem engendrar uma inteireza em termos formativos. Em outras vezes nos deparamos com a fadiga das fragilidades e de processos não efetivados. Como educadores não sabemos mesmo se a metade e o inteiro são um bom binômio para discutir a docência e a avaliação. De toda forma isso se deve à impossibilidade do controle aos moldes do absoluto, ao fator "surpresa" que todo e qualquer processo formativo ou educativo encerra. Assim a prática daavaliação da sala de aula se tece pelos fios de uma tensão entre um "polo externo" representado pela cultura, encarnada na figura do professor, e um "polo interno", representado pelas estratégias individuais (cognitivas e afetivas) de aprendizagem, além das impressões subjetivas que emanam tanto de um polo como do outro.
\end{abstract}

Palavras-chave: Avaliação; Docência; Educação. 


\title{
BETWEEN HALVES AND TOTALS
}

\begin{abstract}
Current essay discusses the evaluation concept and takes into account the frequently intensive learning perspectives that seem to produce a totality in formation terms. In other times, the weariness of the fragilities and non-successful processes may be observed. Educators do not know that the half and the whole are a good binomial to discuss teaching and evaluation. The above is due to the control of absolute moulds and to the surprise factor that lie within all types of formation or education processes. The classroom evaluation process is woven by a tension between the 'external pole', represented by culture and embodied in the teacher, and an 'internal pole' represented by individual cognitive and affective strategies of leaning, coupled to subjective impressions derived from one pole and another.
\end{abstract}

Keywords: Evaluation; Teaching; Education. 
Ao finalizar um semestre como educadores na universidade - mas, imaginamos que em qualquer outra condição da docência - a imagem que temos é a da incompletude: algo foi possível fazer, mas um tanto não foi realizado. Ficam metades para analisar, enfrentar ou ainda outrassubdivisões. Por vezes somos nós professores que não alcançamos o desejado e tantas outras vezes são os alunos. Felizmente, noutras vezes uma aula no decorrer desse mesmo semestre parece lembrar outra imagem que poderia ser destacada pelointeiro. Alguns momentos são tão intensos e raros que parecem engendrar uma inteireza em termos de aprendizagem e de curiosidade saciada. E isso compensa, em parte, a fadiga diante das incompletudes.

Como educadores não sabemos mesmo se a metade e o inteirosão um bombinômio para discutir a docência e a avaliação. Pelo menos não são suficientemente capazes de revelar as travessias de uma sala de aula quando utilizados separadamente. Mais do que isso, talvez possa valer mais à pena destacar múltiplas travessias entre as metades e as inteirezas. Um professor vive essa trama imprevisível: a aula que reclama vida e a aula que a esbanja.

A presença de cada aluno na sala de aula tem uma forma própria: alguns sempre ou quase inteiros, outros pela metade ou "ausentes", uns curiosos, outros silenciosos e bons observadores, uns arredios testando ainda a experiência que acaba acontecendo enquanto aprendem. O fato é que "nunca estão todos" (Caetano Veloso). Não existe apenas a metade e nem o inteiro, como então avaliar o que acontece em uma sala de aula para cada aluno? Para cada professor?

Ainda que as práticas educativas estejam e devam estar relacionadas a métodos, técnicas ou estratégias de operacionalização de um conteúdo ou de um valor sabemos que tudo isso é falível. Mesmo em se tratando de crianças - as quais, pela espécie e por tradição, temos que acolher e conduzir - aquilo que se espera não é, de maneira alguma, garantia. Muito provavelmente isso se deva ao caráter inconclusivo quantos a

Olh@res, Guarulhos, v. 2, n. 1, p. 109-123. Maio, 2014. 
fins previamente demarcados, à impossibilidade do controle aos moldes do absoluto, ao fator "surpresa" que todo e qualquer processo formativo ou educativo encerra, apesar do otimismo pedagógico que sempre "pairou" sobre as mais diversas teorias e os mais variados métodos quanto a resultados, e isso em todos os tempos. Para nosso “azar" e também para nossa sorte, a educação não passa e nunca passará de "aposta", ainda que empreguemos nossos mais esperançosos lances nesse jogo. No Emílio (1762), Jean-Jacques Rousseau já nos alertava quanto à dimensão incerta da educação definindo-a como "arte" e, portanto, não com uma ciência em sua forma usual de expressão:

Portanto, uma vez que a educação é uma arte, é quase impossível que ela tenha êxito, já que o concurso necessário ao seu sucesso não depende de ninguém. Tudo o que podemos fazer à custa de esforços é nos aproximar mais ou menos do alvo, mas é preciso sorte para atingi-lo. (1999, p. 9).

Nietzsche - consideradas as diferentes pulsões e correntes culturais que informam sua filosofia - também atacou o lugar e o valor das totalidades na formação humana problematizando ainda mais a questão. Do seu ponto de vista, tudo que nos captura totalmente e por todo o tempo não tem grande importância. É mais crença do que afeto ou desejo. Uma "captura" nos moldes da crença significaria, nessa perspectiva, a morte do outro. Perder respeito pelo Todo é uma expressão do autor e implica aversão às metanarrativas em função da pretensão de serem claras, objetivas, explicativas, justificáveis, plenamente duradouras. E as metades? Talvez sejam mais humanas, se tomadas pela incompletude ou pela intensidade que, por vezes, pode ser experimentada num processo formativo. Para nós, professores que precisamos avaliar, detectar certos aspectos da incompletude parece mais fácil, mas o quanto de intensidade uma avaliação pode capturar?

A resistência ao todo exerce uma vontade de potência que acumula força para criar, convoca o cérebro e o corpo para habitar o mundo e realizar a sua verdadeira destinação. Afirma Nietzsche que "[...] o homem científico é a continuação do homem artístico" (2005, p. 141). 
Continua persistindo sua crítica àqueles que reduzem a ciência a uma convicção, a uma crença. O mais belo no espírito científico é o rigor do tratamento da curiosidade, a satisfação de quem com ele trabalha e pesquisa, diferentemente de quem apenas recebe os resultados da ciência de um modo mecânico, de um modo que dispensa a reflexão, o jogo e a alegria. Ele mesmo dá um exemplo: deixamos de nos divertir ao aprender a formidável tabuada, porque já não mais aprendemos com curiosidade, parecendo ser suficiente repetir o que já se descobriu. Assim, para ele,

\begin{abstract}
O valor de praticar com rigor, por algum tempo, uma ciência rigorosa não está propriamente em seus resultados: pois eles sempre serão uma gota ínfima, ante o mar das coisas dignas de saber. Mas isso produz um aumento de energia, de capacidade dedutiva, de tenacidade, aprende-se a alcançar um fim de modo pertinente. Nesse sentido é valioso, em vista de tudo o que se fará depois, ter sido homem de ciência. (NIETZSCHE, 2005, p. 161).
\end{abstract}

A aceitação da dimensão trágica na vida e especialmente da vida na sala de aula é um combate aos discursos proféticos, excessivamente otimistas e uma adesão a um movimento que contempla os declínios e a ascensão como espaços de aprendizagem. A sala de aula parece mesmo encarnar essa dualidade; por vezes ela anima e, por vezes, ela frustra. Aquilo que é produtivo nela cansa e morre nos obrigando a fixar novas formas de acordá-la, de fazê-la vibrar. E morre de novo, frustrando, decepcionando e nos obrigando a criar outros e novos desafios.

A sala de aula carrega, assim, o seu "duplo" e é possível recorrer aqui a uma outra de suas dimensões, a "erótica": compreendida como espaço privilegiadoou energia espiritual para o progresso intelectual e sensível, é marcada simultaneamente pelos signos da "opulência" (saciedade ou ausência de desejo) e da falta (desejo), ora germina e vive, ora morre, para de novo renascer. Transita, pois, entre viver, morrer e ressuscitar. Na verdade, o que acontece numa sala de aula se tece pelos fios de uma tensão entre um "polo externo" representado pela cultura, encarnada na figura do professor, e um "polo interno",

Olh@res, Guarulhos, v. 2, n. 1, p. 109-123. Maio, 2014. 
representado pelas estratégias individuais (cognitivas e afetivas) de aprendizagem, além das impressões subjetivas que emanam tanto de um polo como do outro, num lugar que, através dos tempos, constituiu-se como "objetivo". Nesse sentido - e apenas nesse - pode ser compreendida como um "campo de luta", onde polos, ao mesmo tempo "opostos" e complementares, interagem, tanto nas conquistas como nas vicissitudes. Isso parece importante para que a avaliação, tema em exame, não degenere facilmente em retórica moral e emocional.

A recusa por um discurso que procura por "algozes" e "vítimas" no processo avaliativo pode apontar, por consequência, para um entendimento que não só rejeita uma fórmula maniqueísta para examinar o problema, mas também para outras percepções.

Nessa direção, parece, às vezes, que o semestre - intervalo de tempo com começo e fim - salva a sala de aula. Por ter prazo de validade, sabemos - nós e os alunos - que ele finda. O semestre que é a metade do ano. Nele cabe mais uma metade: metade de qualquer dia da semana, já que os horários de aula sempre são parciais. O tempo curto do calendário, com suas divisões e subdivisões, é, paradoxalmente, um alívio, apesar de reclamarmos dessa curta duração para darmos conta dos programas e de planos de ensino. E se pudéssemos imaginar a sala de aula que nunca acabasse? Se tivéssemos que ficar juntos para sempre com nossos alunos e eles conosco? A medida do tempo, que registra metades e inteiros, mornidão e intensidades, a qualidade efêmera dessas relações,em parte nos afasta para garantir os afetos de ambos os lados. À distância, o final das aulas nos faz mais próximos, pois ao invés da totalidade da presença são as metades de cada um que se dissipam, deixam rastros ou não, para outras vezes emergiremem outras vivências, em outro tempo.

"Uma cultura superior, diz Nietzsche, deve dar ao homem um cérebro duplo, duas câmaras cerebrais, uma para perceber a ciência, outra para o que não é ciência; lado a lado, sem se confundirem, separáveis, 
estanques; isto é uma exigência de saúde" (Safranski , 2005, p. 158).

De novo metades, ou dois todos, mas, de fato, presença e ausência.

Convivência entre partes. A "divisão" - não como aplicativo, mas como princípio - cabe bem a nós educadores: metade do cérebro como câmaraque abriga conteúdos, desejos de ensinar, metas a atingir, leituras a realizar. Outra câmara para escapar de tudo isso, dos alunos, para então usufruir do que não é aula, para voltar a "sabê-la" outra vez, reencontrá-la; pensar de novo como praticar a docência, mistura de banquete e de enjôo, de cheio e de vazio, se nos inspirarmos numa passagem do Emílio sobre o homem exclusivamente "feito" de ciência e se acreditarmos que isso seja mesmo possível:

\begin{abstract}
Mas, se considerais a ciência em si mesma, entrais num mar sem fundo, sem margens, cheio de recifes; jamais escapareis dele. Quando vejo um homem apaixonado pelos conhecimentos deixar-se seduzir por seus encantos e correr de um para outro sem saber parar, é como se visse uma criança na praia colhendo conchinhas e começando por guardá-las; depois tentada pelas outras mais que vê, deixá-las de lado, voltar a pegá-las, até que, esgotada pela multidão de conchas e já não sabendo mais o que escolher, acaba jogando tudo fora e voltando de mãos vazias." (1999, p. 211).
\end{abstract}

A imagem de Rousseau, em termos de um valor heurístico para filosofarmos sobre a aquisição de conhecimentos, encontra nas palavras de Paul Diel, ao tratar do simbolismo do titã Prometeu, uma interessante ampliação:

Compreender o sentido profundo da revolta do 'TitãIntelecto' contra o espírito [Zeus], simbolizado pelo 'ladrão de fogo que é trazido aos homens' significa entrever o mais claramente possível as consequiências da intelectualização e de sua tendência ao esquecimento da vida." (1991, p. 224).

Mas deixemos as consequências mais amplas de uma "intelectualização exaltada" e retornemos às "câmaras cerebrais" de Nietzsche.

Uma das câmaras seria a fonte de energia, e a outra, uma espécie de regulador. Esse regulador, constituído pelas paixões e/ou instintos, aquece a fonte de energia, mas também a calibra, pois evita o superaquecimento. Isso significa que é preciso preservar o prazer, a

Olh@res, Guarulhos, v. 2, n. 1, p. 109-123. Maio, 2014. 
paixão, a ilusão pelo acesso à verdade para manter acesa a curiosidade rigorosa e não sucumbir à barbárie do já estabelecido. A metade que não sabe, que é curiosa, que deseja afastar-se de qualquer totalidade.

Quando é chegada a hora da avaliação também se aproxima um tempo em que sentimos uma certa fadiga em relação às aulas. A avaliação que deseja conhecer o que ficou de um semestre em alguma medida tem o gosto de finitude. Já é tempo de abandonar os alunos, deixar aquele dia da semana, aquele horário e evitar o superaquecimento da câmara que abriga os conteúdos e os processos de aprendizagem. $\mathrm{O}$ excesso de vozes, de luzes incandescentes, de textos, de perguntas, de explicações, começa a impedir uma reflexão mais demorada e retira do horizonte a possibilidade deassistirmos, sem pressa, a decantação do que foi e do que não foi aprendido. Os espaços, inclusive os acadêmicos, parece, precisam sempre de recheios para existirem aos nossos olhos e ao nosso pensamento. Mas, uma sala vazia e silenciosa não provoca nada em nós ou nada tem a nos ensinar? Quantas vezes, ao final de um semestre, já nos surpreendemos sozinhos olhando as cadeiras-carteiras vazias e imaginamos que, por alguns minutos atrás, passaram por elas tantas metades e tantos inteiros, passamos também nós pela metade e por inteiro, ao mesmo tempo em que nos perguntamos sobre o sentido do que houve ali. Uma sala vazia e silenciosa é um risco, sem dúvida. Porque pode nos levar a conclusões cruéis, mas também pode ter seu encanto, já que deixou no vazio um mistério e uma experiência que, boa ou má, já se foi. Outra experiência está por vir.

Valeria perder o respeito com esse todo cheio para pensar no vácuo e olhar de novo para as perspectivas. Para saber o que desejamos lembrar e o que merece ser esquecido. Ambos, a lembrança e o esquecimento, carregam uma intensidade que podemos qualificar de formativa em nosso devir docente. 
Depois das aulas e da avaliação, habituar o olho, como diz Nietzsche (2006, p. 60), “ao sossego, à paciência, a deixar as coisas se aproximarem; adiar o julgamento, aprender a rodear e cingir o caso individual de todos os lados". Aprender a ver significa ficar mais vagaroso, mais lento, desconfiado para efetivamente mergulhar nas circunstâncias e refletir. Escapar das vozes das salas de aula para reencontrar o silêncio.E do silêncio pensar outras vivências.

É bom celebrar o final dos períodos acadêmicos, calar depois de tantas vozes, deixar de explicar, controlar, mediar. Tomar avaliações parciais para enfim fechar o diagnóstico: alunos aprovados e reprovados. Sem ressentimentos, caso o realizado tenha sido tão honesto quanto o diagnóstico.

Mesmo com anos e anos de experiência docente, nunca deixamos de nos surpreender com o que nos entregam os alunos ao final do semestre. É nessa hora, sentados em nossa mesa de trabalho, lendo e anotando observações nas folhas A4 digitadas em Arial 12 ou em folhas pautadas, suporte dos mais variados tipos de caligrafias - que nos entregam com olhos que oscilam entre o risível e o sério - que passamos os melhores e os piores momentos da avaliação. Entre o “será que eu falei, durante um semestre, para as paredes?",ou “parece que aqui houve aprendizado" e "de fato, além do aprendizado, o aluno pensou e 'fez' algo com isso" há o que resiste a esses estágios e nos convida a pensar em estratégias cada vez mais sofisticadas de avaliação para classificar os diferentes graus de apreensão do conhecimento estabelecido pelo programa e plano de ensino da disciplina. Evidentemente que não estamos falando do "recorta e cola" ou mesmo de cópias inteiras de textos - por vezes de qualidade para lá de duvidosa - disponíveis em sites da internet, mas daquela atitude honesta que alguns alunos tem quando se trata de compreendere expressar algo novo ou difícil, ainda que com sérias dificuldades de construção gramatical a serem, evidentemente, enfrentados e resolvidos por eles. 
A avaliação propõe o clássico problema do "o quê avaliar" e o "como avaliar", problema ainda a reclamar soluções que, convenhamos, são sempre pela metade e nunca inteiras. Sim, porque não há uma fórmula tão completa a ponto de transformar numa medida objetiva o significado inteiro da passagem do aluno por nós se tomarmos o largo sentido da formação. No máximo, podemos verificar aqueles objetivos ligados à instrução propriamente dita, mas sabemos que eles nunca vêm sozinhos. De qualquer modo, se nossos limites estão circunscritos ao que é passível de verificação, nossa generosidade está na preservação daquela parcela de liberdade que o aluno deve ter para construir um pensamento próprio e "pensamento próprio" não se quantifica e não se controla: se assim for, estaremos pisando e trabalhando no terreno pantanoso das imposições ideológicas, do dogmatismo e da doutrinação.

Diante dos aspectos assinalados até aqui, como sair de cena reservando uma metade saudade, outra metade satisfação com o fim? Como vimos, a sala de aula precisa "morrer" a cada semestre para proteger nossa vontade de potência. Como nos proteger da ilusão de completude exigida poruma sala de aula? Quem sabe, tendo a coragem de fazer desmoronar das inteirezas, vivendo as suas metades, inclusive a da avaliação. Nesse contexto, a parcialidade da avaliação e seus supostos defeitos são em parte a intensidade possível das vivências materializadas. A avaliação não tem e nem pode ter compromisso com a plenitude, não pode contemplar tudo que possa ter ocorrido na sala de aula, mas pode recolher os rastros deixados pelos conteúdos mostrados e pelo convívio que alunos decidem ter (ou não) com os mesmos. Uma boa avaliação é uma oportunidade para que o aluno expresse sua experiência particular com aquilo que o provocou a aprender. Nada existe na avaliação que seja bondoso a priori, ela é um espaço "amoral" do tempo do aluno para desencadear e revelar o que o tempo de estudo permitiu. Também nada é a priori perverso na avaliação, pois ela revela o vivido e o faz por capítulos: o da frequência, da participação, dos trabalhos, das provas, das

Olh@ res, Guarulhos, v. 2, n. 1, p. 109-123. Maio, 2014. 
recuperações, dos seminários, das escritas, das leituras. Num número ou numa só letra (conceito) cabe "tudo" isso. A matemática é por excelência a ciência das sínteses. Um número ou uma letra é um "compacto" de todos esses capítulos da avaliação e não deixam de proporcionar um certo conforto, sempre acompanhado daquela ilusão de exprimir o todo...

Que experiência da sala de aula cada um de nós desejaria que retornasse?

Como diz Nietzsche será preciso ruminar, deixar que as coisas se aproximem para pensar com sossego e tempo para então fazer fluir e afirmar experiências para guardar, metades para entender,"totalidades" para fragmentare outra vez remontar, na esperança de repetir (lembrança) e inovar (esquecimento) nas aulas que ainda virão.

O docente que esbanja vida na experiência de formar não tem receio da avaliação. Da mesma forma os estudantes. Docentes também revelam metades fortes e frágeis, metades ensinadas, metades aprendidas. Como docente somos tocados pela vibração de alguns, apatia de outros e acabamos meio a flor da pele e, por vezes, cansados, com vontade de apagar a luz e bater a porta da sala. Mas, se a finitude nos causa uma ponta de melancolia, não apaga da memória a metade intensidade vivida.

Bachelard em seu livro o Ar e os Sonhos estabelece a dimensão estética das asas como uma resposta a nossa natureza terrestre. As imagens aéreas são conquistas tardias e em seu itinerário enfrentam diversos desafios. "O dinamismo do ar é insultado pelo espetáculo do pássaro prisioneiro", ou como dizem os livros proféticos citados por Bachelard: um pintarroxo na gaiola enfurece o céu inteiro.

Talvez nossa metade revelada em sala de aula seja ainda nossa porção terrestre. O pensamento ainda tem outra forma que, próximo das asas, nos faz lembrar que o pensamento é feito por seu próprio movimento. O golpe da asa é o golpe de nossa capacidade para pensar. Parece a Olh@ res, Guarulhos, v. 2, n. 1, p. 109-123. Maio, 2014. 
travessia da metade terrestre para a metade aérea no desejo de totalidade, mas ainda não é essa a expectativa das asas. A estética das asas não tem como propósito delimitar espaços plenos, indica muito antes o valor do movimento permanente. Apreciar a asa significa reconhecer sua capacidade de vôo e nessa direção provocar os deslocamentos possíveis.

As asas não podem todo espaço decifrar, podem, sim, cartografar itinerários de movimento para reconhecer suas outras tantas metades.

O sentido da avaliação é, em seu sentido mais pleno, o de provocar a mobilidade, os deslocamentos, para descobrir outras formas de estudar, de escrever, de ler, de produzir academicamente. O equívoco da avaliação é insistir na expectativa de ver confirmadas algumas imagens ou algumas grandezas previamente definidas e alçá-las a "ponto de chegada". As grandezas previstas, desejadas são e não são reais, pois precisam de nossa reconfiguração como sujeitos docentes e discentes. A função da avaliação, embora se oriente por padrões, não é o de fixá-los, mas ser capaz de aferir acertos e produzir novos itinerários. A avaliação também não é a priori antipedagógica, como se seus formatos e suas consequências inevitáveis o fossem, mas da exclusão, da punição ou ainda da repressão. Precisamos exercitar e até mesmo inventar processos avaliativos que nos ajudem a ensinar e aprender a avaliar se o que ensinamos - na sua tradução clássica de "enviar sinais"- produziu ou não marcas. Dizer que aprender e avaliar só fazem sentido quando o processo implica prazer é um engodo. Aprender pode implicar o prazer, sem dúvida. Mas pressupõe, também, o embate com o velho e o novo, com o conhecido e o desconhecido. Pode ser e, muitas vezes é um processo penoso. Contudo, necessário. Isso lembra um dos comentários críticos que Mme D’Epinay - que viveu na primeira metade do século XVIII e foi amiga de Rousseau - dirigiu ao próprio tratado de educação escrito pelo amigo quando desconfiou da eficácia do "aprender brincando": garantiu ela que em suas experiências pedagógicas concretas, só foram bem-sucedido aquele que forçou, pela aplicação e pela assiduidade, a

Olh@ res, Guarulhos, v. 2, n. 1, p. 109-123. Maio, 2014. 
vencer as dificuldades e, de fato, aprender (apud Badinter, 2003, p 367). Ainda que possamos discutir esse comentário da perspectiva da educação de crianças em contextos não formais, causa - no mínimo admiração, o fato de, em termos modernos e contemporâneos, esse tipo de prescrição migrar para o contexto universitário no qual se encontram adultos que há muito já deveriam ter aprendido a separar o jogo ou a brincadeira do trabalho e das renúncias que ali lhe são exigidos.

Avaliar, nesse contexto que envolve o encontro de adultos, não significa repetir o que fracassou, mas ao defender a necessidade da avaliação, definir férteis padrões de qualidade para acrescentar às que já demonstraram um relativo valor, outras cartografias da aprendizagem, que possam alavancar a mobilidade dos sujeitos em busca do aperfeiçoamento dos processos educativos.

Nessa rota de navegação, existem riscos, perigos, imprevistos com os quais precisamos contar e sabemos que avaliar implica definir um nível de exigência e assumi-lo. Ao mesmo tempo, exige critérios que, por sua vez, são falíveis. É, pois, uma prática carregada de ambivalência que, para complexificar, conta com princípios e metas comuns aplicadas às individualidades.

A formação, portanto, não significa dar um mesmo formato a sujeitos distintos, mas significa sensibilizar cada um a assumir sua própria possibilidade. Para assumir tal possibilidade, por vezes é necessário “combater o que já se é”, ainda que esse esforço não esteja, necessariamente, inserido em nenhum propósito emancipador.

A formação tem uma relação com a invenção, com a capacidade criativa dos seres humanos, com a arte. Da mesma maneira, a avaliação. Ambas não se vinculam a uma busca estéril pelo autoconhecimento vinculada à arrogância de quem se constituiu sozinho, mas têm relação com as experiências pelas quais passamos e como elas nos tocam.

Olh@res, Guarulhos, v. 2, n. 1, p. 109-123. Maio, 2014. 
A avaliação é um tema pedagógico por excelência, compromisso de todos os educadores e sem dúvida um tema de pesquisa que deve nos provocar a pensar os processos formativos que estão sendo vivenciados nos diferentes ambientes educativos. 
Referências

BADINTER, Elisabeth. A ambição feminina no século XVIII. São Paulo: Discurso Editorial/Dona Dueto/Paz e Terra, 2003.

DIEL, Paul. O simbolismo na mitologia grega. São Paulo: Attar, 1991.

NIETZSCHE, Friedrich. Crepúsculo dos ídolos ou como se filosofa com o martelo. Trad. Paulo César de Souza - São Paulo: Companhia das Letras, 2006.

Assim falava Zatratustra. Um livro para todos e para ninguém. Trad. Mário Ferreira dos Santos. - Petrópolis, RJ: Vozes, 2007.

ROUSSEAU, Jean-Jacques. Emílio ou Da Educação. São Paulo; Martins fontes, 1999.

SAFRANSKI, Rüdiger. Nietzsche. Biografia de uma Tragédia. Trad. Lya Luft. São Paulo: Geração Editorial, 2005. 